\title{
Um roteiro atemporal: reflexões sobre a música, os músicos e o ensino musical
}

\author{
Maria Inêz Lucas Machado (UFMG, Belo Horizonte, MG) \\ marinez@musica.ufmg.br
}

Resumo: Trata-se de um estudo reflexivo e comparativo a partir de textos de três principais referências, o poeta português Fernando Pessoa (1888 - 1935), o maestro italiano Sérgio Magnani (1914 - 2001), radicado em Belo Horizonte em 1950, e o educador inglês Keith Swanwick (1931). Algumas concepções destes autores - e de outros autores e músicos - foram analisadas e diretamente correlacionadas com a prática e a reflexão sobre a música e o ensino musical. 0 processo comparativo entre as diversas ideias e manifestações possibilitou o estabelecimento de parâmetros, apontando fundamentos para as considerações apresentadas sobre a música e também sobre temas como o ensino e 0 desenvolvimento musical, a performance, a criação e a apreciação.

Palavras-chave: autores e idéias, estudo comparativo, música e práticas interpretativas, ensino musical.

\section{A timeless script: thoughts on music, musicians and music teaching}

Abstract: This is a reflective and comparative study of texts from the three main references, the portuguese poet Fernando Pessoa (1888 - 1935), the italian conductor Sérgio Magnani (1914 - 2001), based in Belo Horizonte, Brazil, in 1950, and the English music educator Keith Swanwick (1931). Some ideas of these authors - as well as of other writers and musicians - were analyzed and correlated directly with the practice and thinking about music and music teaching. The comparison process between the various ideas and events enabled the establishment of parameters, indicating reasons for the considerations made about the music and also on issues such as music teaching, development, performance, composition and appreciation.

Keywords: authors and ideas, comparative study, music and performances practices, music teaching.

\section{1 - Introdução}

Estou sempre me despedindo

do ponto de partida que me lança de si,

do ponto de chegada que nunca é aqui. (LUFT, 2005, p.15)

A busca de afinidades e similaridades entre conceitos sobre a atividade artística, constantes no legado de alguns pensadores, estimulou-nos a delinear um roteiro, com o qual fosse possivel transitar em vários sentidos, através de interpenetrações. Na visão do todo ou no exame dos pequenos detalhes, procuramos um percurso circular que realimentasse novas possibilidades, para uma reflexão abrangente. Com o foco introdutório detalhado em alguns de seus textos, escolhemos três autores como principais referenciais neste estudo. 0 primeiro, por ordem cronológica de suas vidas, é o poeta português Fernando Pessoa, nascido no século XIX e falecido no século XX, em Lisboa (1888 - 1935). 0 segundo é o maestro Sérgio Magnani (1914 - 2001), músico italiano graduado também em Letras e Direito. Magnani veio para o Brasil em 1950 e radicou-se em Belo Horizonte, cidade em que se destacou como músico influente e professor de várias gerações, inclusive na Faculdade de Letras e na
Escola de Música da UFMG. 0 terceiro autor é o educador inglês Keith Swanwick, (1931), professor emérito do Instituto de Educação da Universidade de Londres, que acumula ainda as experiências como regente, músico de orquestra e organista em igrejas.

Outras referências de pensadores e músicos, independentemente da contemporaneidade destes com o trio principal, foram acrescidas e entrelaçadas através de aproximações entre os seus discursos, como num contraponto de vozes. Algumas manifestações verbais às quais tivemos acesso, em situações diversas como palestras ou entrevistas, também foram analisadas como elementos constitutivos deste conjunto multifacetado de pensamentos.

Partindo dos três autores mencionados, selecionamos textos de caráter diferente, que contêm reflexões sobre o ser humano diante do objeto artístico, a interpretação e a formação artísticas. Os discursos detiveram a nossa atenção por aspectos tais como o conteúdo expresso, o tratamento poético das idéias e a organização conceitual. Nosso intuito foi o de evidenciar ressonâncias, con- 
vergências e complementaridades entre as convicções apresentadas, cujos fundamentos nasceram de vivências e escopos específicos, com os quais os autores discorreram sobre alguns temas e suas interseções. Este caminho apontou-nos interconexões entre formas aparentemente distintas de descrever aspectos inerentes à atividade artística, contidas nos textos produzidos em diferentes culturas e períodos do século XX. A aproximação entre elas significou o encontro de novos paralelos para a compreensão de aspectos que, isoladamente, já carregam uma densidade própria, quando justapostos ou sobrepostos, denotam maior complexidade em interligações e seus desdobramentos. Neste tipo de triangulação, no qual incluímos outros coadjuvantes, há sempre um trânsito livre e contínuo, como se um pensamento elucidasse o outro e nele estivesse imanente.

\section{2 - Ideias e reflexões: a interpretação, a cria- ção, a apreciação e o ensino musical}

Começamos com um apontamento de Fernando Pessoa, publicado no livro Fernando Pessoa obra poética: organização, introdução e notas (GALHOZ, 1960). 0 apontamento escolhido é uma das Notas Preliminares catalogadas pela organizadora do livro, em trabalho de pesquisa documental e de entrevistas com familiares do poeta, que Ihe cederam material inédito, anexado ao corpo da Obra Poética. Dada a universalidade do conteúdo deste apontamento e o alcance que a ele aferimos, tanto nos aspectos conceituais da arte como também na aplicabilidade destes em alguns fundamentos da educação musical, Pessoa será o elo mais evidente e uma constante referência, projetada direta ou indiretamente. Apresentamos, a seguir, a transcrição integral da Nota Preliminar, que será um ponto de partida no processo comparativo ao qual nos propusemos (GALHOZ, 1960, p.5):

\section{NOTA PRELIMINAR ${ }^{1}$}

"O entendimento dos símbolos e dos rituais (simbólicos) exige do intérprete que possua cinco qualidades ou condições, sem as quais os símbolos serão para ele mortos e êle um morto para êles.

A primeira é a simpatia; não direi a primeira em tempo, mas a primeira conforme vou citando, e cito por graus de simplicidade. Tem o intérprete que sentir simpatia pelo símbolo que se propõe interpretar. A atitude cauta, a irônica, a deslocada - tôdas elas privam o intérprete da primeira condição para poder interpretar.

A segunda é a intuição. A simpatia pode auxiliá-la, se ela já existe, porém não criá-la. Por intuição se entende aquela espécie de entendimento com que se sente o que está além do símbolo, sem que se veja.

A terceira é a inteligência. A inteligência analisa, decompõe, reconstrói noutro nível o símbolo; tem, porém, que fazê-lo depois que se usou da simpatia e da intuição. Um dos fins da inteligência, no exame dos símbo- los, é o de relacionar no alto o que está de acôrdo com a relação que está embaixo. Não poderá fazer isto se a simpatia não tiver lembrado esta relação, se a intuição não a tiver estabelecido. Então a inteligência, de discursiva que naturalmente é, se tornará analógica, e o símbolo poderá ser interpretado.

A quarta é a compreensão, entendendo por esta palavra o conhecimento de outras matérias, que permitam que o símbolo seja iluminado por várias luzes, relacionado com vários outros símbolos, pois que no fundo, é tudo o mesmo. Não direi erudição, como poderia ter dito, pois a erudição é uma soma; nem direi cultura, pois a cultura é uma síntese; e a compreensão é uma vida. Assim certos símbolos não podem ser bem entendidos se não houver antes, ou no mesmo tempo, o entendimento de símbolos diferentes.

A quinta é menos definível. Direi talvez, falando a uns que é a graça, falando a outros que é a mão do Superior Incógnito, falando a terceiros que é o Conhecimento e Conversação do Santo Anjo da Guarda, entendendo cada uma destas coisas, que são a mesma da maneira como as entendem aquêles que delas usam, falando ou escrevendo. (grifos nossos)

Para usufruir mais intensamente das considerações do autor, com as quais tivemos uma empatia imediata, fizemos várias releituras que nos reportaram às concepções de outras pessoas. Durante este trajeto, buscamos ${ }^{2}$ a origem etimológica de algumas palavras, seus diversos significados. Procuramos sentir as aproximações e equivalências entre as conjecturas do poeta e as nossas próprias, com relação à diversidade nas possibilidades de experiência com a linguagem da música e com o ensino. Este processo trouxe à tona várias influências do que já ouvimos, aprendemos, lemos e compartilhamos, na contínua transformação desenhada pela música em nossa trajetória pessoal.

Símbolo, do grego symbolon, pelo latim symbolu, é o que, 'pela sua forma ou natureza, evoca, representa ou substitui, em determinado contexto, algo abstrato ou ausente'; 'objeto material usado para representar coisas imateriais'; 'tem valor mágico e místico.' Em Wisnik encontramos um outro esclarecimento: o símbolo é "o que joga unindo", e se opõe etimologicamente, na sua raiz grega, ao diabulus, ou "o que joga cortando, o que joga para dividir" (WISNIK, 2001, p.8283). Julgamos que uma das formas de jogar unindo, ou aproximando, é o ato de tecer, com os fios disponíveis no exame dos símbolos, as texturas impregnadas de significados especiais. Para entender os símbolos e os rituais simbólicos - que poderíamos considerar no caso da música como requisito primordial para a performance, a apreciação e criação -, Pessoa cita cinco condições indispensáveis a um intérprete, apontando-as, segundo sua própria explicação, por 'graus de simplicidade' e não por uma organização temporal. De fato, ele discorre sobre as suas premissas, partindo da simpatia pelo objeto - condição prévia de quem gosta da atividade que visa realizar - e segue, gradativa e poeticamente, até pousar no campo sensível e elevado da 'conversação com 
o anjo da guarda', ou da 'graça'. Diante da sua organização expositiva, imaginamos que Pessoa tenha evitado o risco de seu texto ser tomado como uma receita que estabelece uma forma padronizada para aquisição dos ingredientes, ou uma seqüência pré-determinada para a sua utilização, com momentos estanques. Após essas considerações iniciais, ele enfatiza que, se o intérprete for desprovido das tais cinco qualidades ou condições, qualquer tentativa de aproximação se mostrará inútil, pois ele será 'um morto' para os símbolos, que igualmente permanecerão na condição de 'mortos'. Estaria assim configurada a impossibilidade de uma verdadeira relação vital nos rituais, justamente pela existência de uma barreira real entre o intérprete e a obra diante dele: nada poderia ser revelado ou vivificado.

A Simpatia, do grego Sympátheia e pelo latim sympathia, tem significados tais como 'afinidade de espírito'; 'participação em'; 'sensibilidade ao sofrimento do outro'; 'conformidade de gênios'; 'compaixão'; 'atração que uma coisa ou uma ideia exerce sobre alguém'. De fato, o intérprete tem que ter simpatia pelo que vai interpretar e estar livre de atitudes impeditivas como a 'ironia, a cautela ou o deslocamento', pois estas o privam da simpatia. 0 processo de escolha de repertório para um músico é crucial e exemplifica, de forma clara, esta questão. Ele tem relação direta com o comprometimento pessoal no estudo da obra, com o resultado expressivo e o valor aferido à interpretação. Da mesma forma, o interesse e a afinidade movem quem está envolvido com a criação ou com a apreciação da música. Trata-se, como preconiza Pessoa, de preservar pela simpatia uma condição de entrega, inerente à relação afetiva que nasce quando o intérprete, 0 compositor e o ouvinte se sentem atraídos, ou arrebatados pelo símbolo (ou pelos rituais simbólicos).

A Intuição, do latim intuitione, 'percepção que se adianta ao raciocínio'; é o ato de ver, pressentir, 'ter percepção ou conhecimento, claros e imediatos, de um objeto na plenitude da sua realidade, seja este de ordem material, ou espiritual'. É quando da contemplação emana uma verdade plena, de natureza diversa daquela obtida através da razão ou do conhecimento analítico. Segundo o poeta, a simpatia não cria a intuição, ela vem auxiliá-la, se esta é uma qualidade que o intérprete já possui. Acreditamos que a intuição permite ao intérprete pressentir algo que está além do símbolo, por conseguinte, se apossar daquilo que não é igualmente perceptível por cada um que venha a se aproximar do objeto. Muitas decisões interpretativas musicais acontecem em domínios onde não existem confortáveis evidências, pois, tais revelações não podem se dar e nem prevalecer, senão em níveis mais profundos. A Inteligência, do latim Intelligentia, é a 'faculdade de aprender, perceber, apreender'; 'astúcia'; 'capacidade de penetração, agudeza e perspicácia'. Como afirma Pessoa, a inteligência analisa, decompõe e reconstrói o material no processo da interpretação, depois que o artista já se valeu da simpatia e da intuição. De discursiva e descritiva, a inteligência passa a ser analógica; engendra recursos e estabelece novas conexões para que o símbolo possa ser interpretado e reinterpretado. Na sua origem latina, inteligência significa "intus legere", ou seja, ler do lado de dentro. Com este tipo de leitura, a inteligência musical constrói relações do 'lado de dentro' e em outros patamares. Aproximar o que aparentemente não está relacionado, ou explícito na partitura, é uma abordagem da obra musical que a simpatia suscita e a intuição celebra.

A compreensão é o conceito apresentado por Pessoa para se referir ao conhecimento de outras matérias que iluminam o símbolo e o relacionam com outros. Apreendemos disto que essas luzes provêm de outros tipos de objetos do conhecimento, de outras conversações, correlações e temáticas. Para se compreender certos símbolos, ele julga ser preciso, antes ou ao mesmo tempo, o entendimento, a vivência de símbolos diferentes. Compreender, do latim comprehendere, significa 'assimilar mentalmente, ter domínio intelectual de um assunto'; 'ter percepção e entendimento'; 'conter em si, incorporar', 'perceber as intenções ou o sentido', 'dar-se conta de alguma coisa'. Nessa perspectiva de incorporação podemos incluir o interesse por símbolos transportados num diálogo entre formas de arte distintas, que, ao se integrarem podem arquitetar novas associações, outros significados, reflexões e descobertas subjetivas. Cremos que, por isto, a compreensão foi o termo escolhido, como justifica Pessoa, e não a erudição significando 'soma', nem a cultura, significando 'síntese'. A compreensão dá autenticidade às realizações expressivas, na performance e na criação, e permite uma escuta musical sensível e ativa. É um resultado de vida interior intensa, da experiência profunda e da incorporação.

A Graça, ou a mão do Superior Incógnito, ou Conhecimento e Conversação do Santo Anjo da Guarda: para Pessoa, estas são algumas das denominações possíveis para a menos definível das cinco condições. Elas designam a mesma coisa - ou recurso, captado em outra dimensão de valor - e são acolhidas da maneira como esta condição pessoal é entendida por quem, mesmo na impossibilidade de descrevê-la ou compartilhá-la, dela se vale para lidar com a linguagem simbólica.

Observamos que as cinco condições necessárias ao intérprete contemplam as dimensões afetiva, intelectual e espiritual do fazer artístico. Na filosofia e na psicologia da educação musical, os pensadores, de uma forma ou de outra, mesmo com desdobramentos teóricos especificos e terminologias diferentes, afins às distintas áreas do conhecimento, tratam sempre estas dimensões como essenciais nos fundamentos filosóficos, sociológicos e psicológicos da música e da educação musical. ${ }^{3}$

Em outras notas soltas, constantes da Obra Poética Fernando Pessoa escreve sobre necessidades humanas e sobre paisagens interiores e exteriores. Ao comentar sobre uma frase gloriosa dos antigos navegadores portugueses - 'Navegar é preciso: viver não é preciso' - ele faz a sua adaptação: "Quero para mim o espírito desta frase, transformada a forma para a casar com o que eu sou: Viver não 
é necessário; o que é necessário é criar" (GALH0Z, 1960, p.XIII). Tendo em conta que a música não pode ser usada para comunicar significados explicitamente, atribuímos o seu poder à necessidade humana de criar e se comunicar através de sistemas simbólicos. Em sintonia com a convicção do poeta, podemos confirmar essa necessidade pelo registro permanente da música no fio condutor da história da humanidade. Ela está presente, com grandiosa variedade, em todos os períodos já rastreados pelo homem em seus estudos e - resguardadas as distintas atribuições de valor e função -, em todas as culturas, de ontem e de hoje.

Ao analisar certas necessidades humanas, instaladas em seu universo interior e expostas no mundo exterior, F. Pessoa faz uma descrição sobre toda atividade mental, especialmente a da criação, e aponta para o que ele chama de:

\section{(...) duplo fenômeno de percepção: ao mesmo tempo que temos consciência dum estado de alma, temos, diante de nós, impressionado-nos os sentidos que estão virados para o exterior, uma paisagem qualquer, en- tendendo por paisagem, para conveniências de frases, tudo o que forma o mundo exterior num determinado momento da nossa percepção. Todo estado de alma é uma paisagem. Isto é, todo estado de alma é não só re- presentável por uma paisagem, mas verdadeiramente uma paisagem (GALHOZ, 1960, p.31).}

Na sua conceituação, Pessoa declara que a arte é a representação simultânea dessas duas paisagens, a interior e a exterior. Ele discute que, mesmo não se aceitando que um estado de alma seja considerado uma paisagem, a arte pode ser admitida como a interseção de "um estado de alma (puro e simples sentimento) com a paisagem exterior"(GALHOZ, 1960, p.31).

Esta consideração nos leva a Howard Gardner, que em sua teoria das inteligências múltiplas trata da inteligência musical e faz uma interessante comparação entre a gênese da composição musical e a da poesia (GARDNER, 1994). O seu pensamento nos permite uma associação com as paisagens apresentadas por Pessoa, as quais 0 processo artístico permite conjugar. $\mathrm{Na}$ análise da inteligência musical Gardner sugere que compositores e poetas se parecem "na súbita apreensão das idéias germinais iniciais, na necessidade de explorá-las, realizá-las e no entrelaçamento de aspectos emocionais e conceituais" (GARDNER, 1994, p.90). Entendemos que essas ideias súbitas tendem a encontrar uma forma de representação no mundo exterior, que é apreendido por meio dos sentidos. Através da manifestação artística, os sentidos direcionados ao meio exterior utilizam e também criam recursos necessários para nele interferir.

Gardner inclui em seu texto as seguintes descrições de outros compositores sobre os processos nos quais se engajam. Para Aaron Copland compor é tão natural quanto comer ou dormir: "É algo que o compositor nasceu para fazer, por isto perde o caráter de virtude especial aos seus olhos". 0 único elemento misterioso, para ele, é a fonte de uma ideia inicial, os temas parecem dons vindos do céu, como na escrita automática. Saint-Saëns compara o processo da criação ao de uma macieira que produz maçãs e Arnold Shoenberg acredita que qualquer ocorrência de uma peça musical "nada é além do que um infindável remodelar de uma forma básica", ou nada além "do que vem do tema, brota dele e pode ser traçado de volta a ele"(GARDNER, 1994, p.80). Gardner acrescenta ainda ao seu texto o pensamento de Schopenhauer: "O compositor revela a essência mais íntima do mundo e profere a mais profunda visão em uma linguagem que seu raciocínio não entende, assim como um hipnotizado revela coisas das quais não tem nenhuma idéia quando está desperto" (GARDNER, 1994, p.81).

Parece haver alguma semelhança entre os pontos de vista acima mencionados e o pensamento do compositor brasileiro, Camargo Guarnieri, que equipara os mistérios da gênese e os processos criativos da composição musical e da literatura, conforme informações que obtivemos recentemente, em depoimento ${ }^{4}$ de Vera Guarnieri. Pessoa e Gardner apontam para a necessidade interna e a busca de satisfação pessoal no ato de lidar com as estruturas composicionais, seja na música, pelos sons, ou na literatura, pelas palavras. A 'apreensão de ideias germinais', no nosso entendimento, é uma outra forma de se referir ao que acontece pela conjunção da simpatia com a intuição. $\mathrm{Na}$ exploração deliberada e consciente do material, o artista se vale de ambas as qualidades e da sua inteligência. A realização ou a percepção da 'combinação de aspectos emocionais e conceituais' depende da compreensão dos significados, alcançada nos patamares superiores da sensibilidade e da inteligência. A nosso ver, assim também acontece a experiência musical profunda dos compositores, dos intérpretes ou dos ouvintes ativos. Segundo Gardner, as questões das diferenças das personalidades são determinantes para a busca das fontes pessoais de prazer. Ao comparar as capacidades musicais com outras competências intelectuais, ele sugere haver evidências de que "assim como a linguagem, a música é uma competência intelectual separada, que também não depende de objetos físicos no mundo" (GARDNER,1994, p.95). Ele explica que na música e na linguagem a destreza pode ser elaborada até um grau significativo, apenas através da exploração e aproveitamento do canal oral-auditivo. Não acredita ser mero acidente o fato de que as duas competências, desde o início do desenvolvimento, procedam sem relação com objetos físicos e baseiem-se ambas, de maneiras neurológicas distintas, no sistema oral-auditivo.

Parece-nos que as competências artísticas correspondem à vitalidade de um mundo interior independente, com suas próprias paisagens, apesar de conectado com o meio exterior, no qual encontra múltiplas formas de se expressar. Cecília Meireles, no prefácio do livro Cartas a um Jovem Poeta (RILKE, 1999), depura alguns aspectos tratados pelo autor, que nos parecem condizentes com a conquista de um espaço criativo internalizado. Ao comentar sobre a 
essência dos conselhos dados por Rilke ao jovem escritor, ressalta algumas atitudes que ela considera como prevalentes, e, por isto, devem ser cultivadas e valorizadas pelos artistas: "um gosto pela solidão constante e inteligente" e "uma disciplina poética humilde e vagarosa" (RILKE, 1999, p.12).

Em seu livro Expressão e Comunicação na Linguagem da Música, (MAGNANI, 1996, p.61-67), o maestro Sérgio Magnani explica: interpretar (do latim inter petras, ou entre as pedrinhas) é "o ato de descobrir e comunicar significados que podem estar ocultos por detrás de uma série de significantes fundamentais" (p.61). Ler nas entrelinhas, ou 'ler do lado de dentro', é perceber o que não está explícito. Ele compara esta leitura com a dos adivinhos, que nas configurações de pedrinhas, borras de café ou cartas do baralho percebem sinais do destino e fazem previsões do futuro. A interpretação para o maestro pode ser descrita como: "Atividade, portanto, de intuição e técnica, baseada no reconhecimento dos símbolos e dos caminhos misteriosos da sua gênese, a fim de se chegar $\dot{a}$ tradução dos símbolos em eventos ou fenômenos, em nosso caso, sonoros" (MAGNANI, 1996, p.61).

Segundo o autor, são apoios para o intérprete a cultura, a sensibilidade e a tradição. A cultura, que em Pessoa também é 'síntese', é conceituada por Magnani como preparo filológico e conhecimento estilístico. Mas, com a ressalva de que este último requer uma penetração com o espírito, livre de preconceitos arraigados, das "falsas e pomposas regras" e da rigidez preconizada por determinados historiadores. Desta forma, o intérprete deve alcançar o equilíbrio entre cada estilo e a sua própria sensibilidade, além de ser capaz de integrá-la à sensibilidade do autor e da obra. Semelhante ao expresso no pensamento de Pessoa, esse processo apontado pelo maestro nos confirma a inteligência musical analógica, a simpatia pelo símbolo e pelos rituais simbólicos e a intuição como agentes motivadores e propulsores para uma boa realização musical.

Também em Magnani reencontramos a avaliação de que a compreensão é a condição para a autonomia e a personalidade do intérprete. Referindo-se à tradição, ele também alerta para o fato de que "ela pode alimentar o espírito da obra, assim como pode, também, coagulá-lo em esquemas sem vida" (p.66). Por isto, esclarece em seu texto que é preciso integrá-la com lucidez a uma avaliação crítica e também aos questionamentos culturais. Neste sentido, na relação entre o intérprete e a composição musical há aspectos abordados pelo maestro, que merecem a nossa atenção. Quando se refere à produção do compositor ele ressalta:

(...) a obra acabada se destaca do autor, adquirindo vida própria; em certo sentido, não mais pertence ao autor. É um campo aberto de possibilidades às suas próprias concepções de intérprete. A obra é um novo astro - ou apenas um asteróide - que se acrescenta a uma outra constelação no puro céu da arte: o artista só começa a viver na obra de amanhã, que está a fecundar a sua fantasia (MAGNANI,1996, p.65).
Para Magnani, o bom ouvinte deve esperar do intérprete que este não invada indevidamente a obra com a sua personalidade. 0 equilíbrio está em se respeitar os mestres, a tradição, as escolas e o meio cultural, visto que estes não podem ser ignorados, mas, tão pouco, devem ser aceitos sem reservas, ou questionamentos. Se a obra musical tem vida própria, a relação é de fato delicada:

Parece, às vezes, que o intérprete revela a obra, acrescentando algo que é só dele. Isso, porém, é ilusão: ele apenas descobriu uma potencialidade da obra que aos outros havia escapado. Um grande mérito, sem dúvida, mas sempre subsidiário ao conteúdo implícito no texto (MAGNANI,1996, p.66).

Quanto a esta consideração, acrescentariamos que é muito tênue, ou impreciso, o limite entre a invasão indevida e as descobertas individuais. É difícil se estabelecer o ponto onde uma começa e a outra termina, com objetividade e argumentação irrefutável. Na verdade, com alguma frequência é possivel observar avaliações tão apaixonadas quanto contrastantes a respeito de performances que se destacam pela ousadia e inovação. Músicos experientes realizam diferentes apreciações e julgamentos de valor e, felizmente, a não ser no caso de deturpações evidentes, essa variedade corresponde a uma riqueza de possibilidades que boa obra encerra e o bom intérprete ressalta.

$\mathrm{Na}$ visão do maestro Magnani, o papel do intérprete exige constante "auto-educação, renovação da juventude de espírito, (...) consciente superação do epidérmico para a conquista de zonas mais profundas da sensibilidade" (p.67). Tais zonas talvez sejam aquelas acessadas através da graça, da conversação com o Santo Anjo da Guarda, na visão poética de Pessoa. ${ }^{5}$

Ao abordar filosoficamente a questão, Sandra Abdo coloca-nos diante de uma síntese muito feliz sobre o fenômeno da interação entre o intérprete e a obra, que ajuda a referendar nossas explanações anteriores:

Tratando-se de uma relação dialética, na base da qual estão polos orgânicos, constitutivamente multifacetados, plurissêmicos e inexauriveis, o que, em suma, se pode esperar desse tipo de atividade é, ao mesmo tempo e inseparavelmente, a revelação da obra em uma das suas possibilidades e a expressão da pessoa que interpreta, condensada em um dos seus múltiplos pontos de vista (ABD0, 2000, p.23). (grifos da autora)

Sonia A. LIMA (2006), entende a música como uma arte com essência interior temporal, à espera de realização (p.60-61) e vê o intérprete como aquele que, de certa forma, a recria: "Ele é o elemento intermediário que dá vida à música, dá-lhe uma temporalidade concreta e dá vida aos símbolos expressos na partitura" (2006, p.60). A autora menciona a perspectiva de G. Brelet sobre a problemática existente entre a obra musical, com necessidade congênita de intérprete, e a diversidade possivel de interpretações. Segundo BRELET:

O que separa a concepção da realização é, nem mais nem menos, seu caráter indeterminado e rico de possibilidades. A concepção é um es- 
quema fecundo, um tema gerador. (...) A obra musical não extingue o estado de pensamento puro. A multiplicidade de execuções possíveis, por meio das quais a obra se realiza, atesta em grande parte, seu caráter inacabado e todas as possibilidades que se encontram intactas na obra (apud Fubini, 1994, p.119; in LIMA, 2006, p.61).

Continuando a explanação acerca da plenitude da obra a ser vivida pela consciência do intérprete, Lima se apóia na visão de Brelet a respeito da partitura: uma virtualidade, ou campo de possibilidades. A música tem uma temporalidade que é vivente, não esquemática ou abstrata e a obra se realiza numa subjetividade essencial e constitutiva. Para BRELET:

A Música tem a mesma dimensão temporal que nós temos (...) a música vive na duração, duração esta que é essencialmente dramática, posto que ela resume, acima de todos os dramas particulares, o drama puro da existência (...) os grandes esquemas da vida interior (apud Fubini, 1994, p.126; in LIMA, 2006, p.62).

Keith SWANWICK discorre sobre os parâmetros da educação musical, em seu livro A Basis for Music Education (1979), e faz um alerta aos professores para que fiquem atentos à efemeridade da música. Devido a esta condição, a música deve ser tratada e compreendida enquanto se afasta no tempo, como se fosse guiada em um tipo de vôo. Esta abordagem - na qual a revelação de uma obra pela expressão do intérprete é como se fosse a condensação, no tempo, de uma das inúmeras possibilidades desse vôo parece se adaptar às concepções de ABDO (2000) e LIMA (2006), acima mencionadas. De fato, perante a uma mesma obra, o músico experiente sabe que, em cada ocasião diferente, ele vai expressar apenas um dos resultados possíveis do seu 'exame dos símbolos'; estes, por sua vez, sendo constitutivos de um outro pólo orgânico - a obra -, não se encontram na condição de 'mortos' para o intérprete. Ao aceitarmos que cada obra e cada intérprete têm as suas idiossincrasias e suas surpresas, somos levados a crer que a apreciação acontece num processo de interação, no qual as experiências de vida e com a música, incorporadas pelo ouvinte, definem os níveis de impacto desta relação. ${ }^{6}$

No ato da criação, as experiências e os sentimentos também se interligam; quem escreve a música, ao mesmo tempo a está submetendo à sua própria apreciação. 0 julgamento crítico do compositor parece buscar uma modalidade de interação entre as paisagens do seu mundo interior e do mundo exterior. Por sua vez, o intérprete coloca-se diante da peça entregando à sua execução, além do seu conhecimento, a intensidade do seu sentimento, para estabelecer laços individuais profundos. Este tipo de comprometimento é, simultaneamente, uma ajuda, tanto na comunicação da obra para o seu ouvinte, quanto na sua própria apreciação musical.

Nas narrativas de dois grandes pianistas brasileiros, de renome e carreiras internacionais, há revelações sobre suas sensações pessoais diante do ato da interpretação musical e suas variáveis temporais e afetivas, sobre o ritual diante de uma platéia e sobre a escuta da obra musical, após a gravação em estúdio. Há alguns anos, ouvimos Arnaldo Cohen em entrevista concedida a uma rede de tele- visão. Na ocasião, ele fez uma descrição instigante sobre a situação de um pianista que sobe ao palco para uma apresentação pública. Para o pianista, o momento é único e de tal delicadeza e profundidade que, nessas oportunidades ele próprio se sentia como que 'despido diante da platéia'. Cohen concluiu a sua análise comparando a vulnerabilidade do artista, naquela fração de tempo em que acontece a performance, com uma espécie de 'strip-tease emocional' feito pelo pianista, que se mostra sem véus diante das pessoas, através da música. Nelson Freire, em entrevista a uma emissora de rádio, explicou o incômodo que sempre sentia ao ouvir suas próprias gravações. Em sua opinião, a gravação era apenas uma forma de congelar no tempo uma versão que ele havia realizado de alguma música, em dado momento. Pela sua experiência, quando ouvia alguma peça que havia gravado, sentia-se incomodado com a constante autocrítica e a constatação de que não tocaria uma ou outra passagem da mesma forma, em outra performance. Na ocasião da entrevista, ele havia lançado um CD recentemente e disse, para exemplificar a sua particularidade, que não havia tomado a iniciativa de ouvi-lo, por falta de interesse. Entretanto, explicou que, alguns dias antes daquela conversa, havia se confrontado (não intencionalmente) com o trabalho, ao ouvir pelo rádio uma programação musical enquanto dirigia o seu carro. Foi quando, de repente, reconheceu uma faixa da sua gravação e disse para si mesmo: "Ih!! Sou eu..." Com bom humor, relatou ao entrevistador que ele "até ficou ouvindo assim, meio de lado"...

Em geral, os músicos em suas avaliações e conversas, falam com entusiasmo sobre a experiência que a música pode representar para cada um e sobre as respostas pessoais que Ihe são dadas. SWANWICK (1979) enfatiza, entretanto, que não há como construir uma relação concreta entre uma melodia, por mais simples que seja, com algo que the seja equivalente, ou com qualquer acontecimento extrínseco. Os músicos, ao que parece, concordam com esta afirmação do professor e vemos aí a confirmação de que, como nas artes plásticas não figurativas, o significante sonoro não possui um significado lógico ou universal. Nas palavras de Swanwick, falar sobre música "como se ela fosse uma coisa simples e única é correr o risco de subestimar sua força potencial e infinita variedade". 0 tratamento da linguagem musical, em qualquer tipo de atividade, "requer habilidade para responder e se relacionar intimamente com o objeto musical como entidade estética. Isso se assemelha com um estado de contemplação" (SWANWICK, 1979, p.42-43). Adverte o autor que a concentração e o comprometimento do músico requerem a 'exclusão virtual' de tudo o que está à sua volta. Realmente, quando estamos inteiramente absorvidos, entregues, somos transformados pela experiência. Neste ponto, novamente nos deparamos com um estado de contemplação, ao qual fomos levados pela nossa vontade e pela simpatia, com a 'conquista de zonas mais profundas' - segundo o maestro Magnani -, ou com a ação da 'mão do superior incógnito' - de acordo com F. Pessoa. 
Quando Swanwick apresenta sua base para a educação musical, usa o mnemônico C(L)A(S)P para estabelecer referências às atividades de criação $(C)$, apreciação $(A)$ e performance $(P)$ na formação musical, amparadas pelos estudos de literatura da música e sobre a música (L) e pela aquisição de habilidades específicas para as práticas musicais (S - Skills). Ele esclarece que este modelo é somente uma formulação teórica do que acontece numa boa prática de ensino musical e do que falta, quando 0 ensino é ruim. Concordamos com o autor quanto à validade da aquisição de habilidades técnicas, dos estudos teóricos e musicológicos, do treinamento auditivo e de leitura. Estes são exemplos de recursos importantes e indispensáveis, que devem ser considerados como alguns dos meios através dos quais se dá a formação musical seja qual for a perspectiva profissional daqueles a quem esta preparação é direcionada. Não devem, entretanto, constituir-se como uma finalidade em si. Esforços concentrados somente nesses enfoques, tratados de forma desarticulada, caracterizam uma educação musical fragmentada e restritiva, a qual, não raro, pode conduzir às seguintes situações: a interpretação que não envolve 0 público, que, por sua vez, não percebe o envolvimento do intérprete; a composição que, mesmo bem estruturada, não alcança a comunicabilidade; a escuta superficial, sem impacto significativo. Em outros termos, a 'soma' da erudição, com acúmulo de habilidades e de informações sobre música, ou a 'síntese', processada no domínio de certos aspectos históricos e culturais, não significam, tanto em Swanwick, como em Pessoa e Magnani, o alcance da expressão humana através da linguagem artística e a vivência profunda do prazer estético.

Para a interseção entre as paisagens interior e exterior, descritas por Pessoa, não basta a inteligência, discursiva ou analógica, que pode se manifestar na contextualização histórica da obra, na análise musical minuciosa e descritiva, na técnica primorosa de execução instrumental ou de escrita composicional. No nosso ponto de vista, para a exploração do universo criativo do indivíduo e expansão do seu potencial expressivo, a inteligência deve atuar com o suporte de um conjunto de condições, tais como: o amor pela arte, a intuição, o prazer das descobertas, a liberdade de escolhas, a conquista de zonas mais sensiveis, ou experiência em estados de contemplação. Sem estas condições, o intérprete, o ouvinte e o compositor continuarão distantes dos símbolos e estes, apartados deles; o entendimento pleno e individual não terá como desabrochar. É pouco provável que experiências isoladas na formação musical resultem em um comprometimento pessoal, pois elas não se integram e nem se iluminam. Assim, habilidades técnicas adquiridas e confinadas em certos tipos de adestramentos, servem, a nosso ver, apenas para a realização de reproduções musicais impessoais, padronizadas e inexpressivas.

Encontramos em Rubem Alves reiteradas críticas ao culto dos meios, em detrimento das finalidades, principalmente com relação à educação formal. Ele revela suas preocupações quanto à valorização exacerbada da aquisição de saberes, que resvala para o culto ao adestramento dos alunos, sem a construção de um gosto refinado pela descoberta, ou pela criação de sabores. No seu entendimento, a inteligência é a nossa capacidade de conhecer e manipular o mundo, por isto, tem a ver com aquisição do poder. Por outro lado, a sabedoria tem a ver com a felicidade, pois "é a graça de saborear o mundo" (ALVES, 1997, p.53). Revemos em Alves a opinião de que inteligência nos fornece os meios importantes, mas é a sabedoria que nos dá motivação para viver. Ele compara o cérebro a uma caixa de ferramentas e conclui que a inteligência não corresponde à posse de um arsenal destas, mas à capacidade de andar leve, carregando apenas algumas, escolhidas segundo a necessidade de cada situação. 0 que importa é saber como procurar e onde encontrar aquelas que, eventualmente, vierem a faltar (ALVES, 2002, p.183). Vimos que, também no seu entendimento, significados específicos alcançados pela inteligência, que podem ser explícitos em outras formas de comunicação, não são prioridades no mundo da arte. Ao discorrer sobre suas repetidas experiências como apreciador musical e na condição de profundo amante da música, ele apresenta conceitos tais como "A beleza não precisa do sentido. Ela salva sem nada dizer" (ALVES, 1997, p.72). Nesta descrição poética percebe-se uma afinidade implícita com os autores anteriormente mencionados, quando ele confere à experiência musical, ou à experiência com qualquer outra forma de arte, um valor humanístico revelado em estados de interiorização sensivel, de maior proximidade com o insondável. Alves enfatiza o poder da música, transitando, com liberdade e metáforas, em outras dimensões: "Deus não está na letra. Está na música. Ou ainda: "(...) o repicar dos sinos (...) é um altar construído com sons. Os sinos fariam o corpo se lembrar de Deus mais que muitos sermões" (ALVES, 1997, p.73-74).

Retornamos a Swanwick, focalizando a educação musical e à procura de ressonâncias entre suas concepções e as dos demais autores e músicos aos quais estamos nos referindo. Quando analisamos o Modelo Espiral de Swanwick e Tillman, vemos o desenvolvimento musical - para a performance, a criação e a apreciação - experimentado num processo evolutivo e circular, em que são agregados patamares diferentes das condições desabrochadas. ${ }^{7}$ Neste Modelo, as dimensões cumulativas do discurso musical são quatro: os Materiais, o Caráter Expressivo, a Forma e o Valor, sendo cada uma delas um estágio de desenvolvimento. As mudanças entre os estágios se amparam na intuição e na aquisição das capacidades analíticas, construídas num processo evolutivo, com a interação das tendências assimilativas e acomodativas. Cada um dos quatro estágios tem dois níveis, o primeiro deles no lado esquerdo - assimilação, intuição, jogo espontâneo, motivação interna -, e o segundo, no lado direito - acomodação, análise, imitação, adaptação ao social. 
Acatamos o fato de que, aquilo que desabrocha, já está internalizado e, num estágio ulterior, passa a ser expresso, ou revelado, desde que haja condições e estímulos para que isto ocorra. A mudança de patamares neste processo evolutivo e circular se dá através dos impulsos possibilitados pela intuição e pela simpatia. Através do interesse, da motivação - ou simpatia pelo símbolo, segundo Pessoa -, há como se explorar os materiais nos níveis sensorial e manipulativo: é possivel viver o aspecto lúdico e ter o prazer inicial. É esta experiência que favorece a inclinação pessoal para interligar sons, fazer imitações ou variações; ela estimula a inteligência ("intus legere") para que o principiante comece a lidar com uma dimensão analítica. A inteligência musical, sempre presente, será necessária no controle dos sons e concatenação das ideias e para a aquisição do caráter expressivo. A espontaneidade da expressão individual nasce da intuição e da simpatia pela atividade, que, amparadas pela inteligência, conduzem ao amadurecimento, galgado em etapas. Nesse percurso, são atingidos graus diferenciados ou no emprego, ou na libertação, paulatina, das convenções e estereótipos. Para a construção de uma forma de comunicação individual, com sua dimensão afetiva, os esquemas pré-existentes serão revisitados no estabelecimento dos processos de assimilação e acomodação do desenvolvimento musical, em sua dimensão cognitiva.

A compreensão é uma qualidade fundamental, quando se lida com as dimensões formal e simbólica da música. ${ }^{8}$ As especulações e os traços idiomáticos, expostos no emprego criativo da linguagem, correspondem à assimilação de convenções, em um campo de imaginação onde já se desenham paisagens interiores. Novas relações são construídas (relacionando no alto, de acordo com o que está relacionado em baixo, segundo Pessoa) e as surpresas (e individualidades) podem integrar-se em estruturas mais complexas. Na nossa percepção, este processo depende da capacidade de compreender, porque ele é mais que somar ou sintetizar. Requer, portanto, para cada estágio de desenvolvimento musical, o amadurecimento, a vivência, e incorporação de processos e de valores.

Ainda analisando o Modelo Espiral, concordamos que é perceptível a conquista de um valor simbólico, importante para a pessoa ou para a coletividade, quando são extrapolados certos padrões e patamares pré-determinados. Para atingir essa liberdade e a personalidade na interpretação musical, parecem-nos também requisitos fundamentais o impulso do espírito, o desejo de superação e a capacidade de ultrapassar superficialidades. Também nesta análise do Modelo Espiral, somos levados a agregar os conceitos dos nossos outros dois principais interlocutores, o maestro Magnani e o poeta Fernando Pessoa. Tentando trazê-los novamente para este diálogo atemporal, parece ser viável entender cada etapa vivenciada na arte musical como vitória da sensibilidade, ou momento de graça.
Como uma decorrência das inúmeras variáveis, qualitativas e quantitativas, justapostas às individuais e interpessoais, a particularidade da avaliação de desempenho musical dos alunos com base no Modelo Espiral não é a aferição exata do seu patamar de desenvolvimento, através de suas manifestações musicais. Por isto, nos deparamos com as aproximações, quando analisamos os resultados produzidos por diferentes avaliadores, mesmo que atuem em número reduzido, a partir do mesmo material. Isto nos confirma que 0 olhar humano voltado às atividades humanas tem, felizmente, a propriedade de ressaltar as diferenças e não enrijecer as categorizações. Isto não significa, entretanto, que os modelos de avaliação nos sejam prescindiveis. Na verdade, eles são produtos de olhares minuciosos e criteriosos, registrados em organizações tão maleáveis quanto abrangentes. $\mathrm{Na}$ variedade de julgamentos encontra-se a oportunidade de interseção entre diversas paisagens pessoais, expostas num meio exterior. Este processo é comparável ao que ocorre quando, após percorrermos em conjunto um mesmo caminho, ao final do percurso, teremos captado e guardado como relevantes aspectos diferentes, de acordo com a influência destes em nossa mente e a resposta da nossa sensibilidade individual. 0 que não existia no roteiro não poderá, de fato, ser descrito, mas, as cores e a intensidade com que faremos as nossas descrições pessoais - ou os eventos que escolheremos para tal demonstrarão a riqueza humana na variedade implícita das nossas percepções.

Julgamos, finalmente, ser possível inferir do Modelo Espiral que, mesmo nos estágios primários da pura exploração sensorial por parte dos iniciantes - ou, mais adiante, quando já são perceptíveis pequenos motivos musicais ou frases organizadas em estruturas simples -, a simpatia pela atividade e o prazer encontrado no entrelaçamento dos sons já significam, numa avaliação estritamente contextual, formas superiores de expressão pessoal. Isto porque, aquele indivíduo, de qualquer idade, que se entrega ao exame ou à exploração dos símbolos e dos rituais simbólicos musicais, não o faz à procura de um significado específico, através de habilidades e códigos já assimilados, mas sim, em busca de uma possibilidade para expressar o seu eu, de revelar as suas paisagens interiores num meio exterior. Essa poderia ser, na visão poética do nosso primeiro interlocutor, uma forma elevada de manter a conversa íntima com o Superior Incógnito, que habita em cada um de nós.

\section{3 - Concepções de músicos professores e as qualidades preconizadas por Pessoa}

Em entrevista, o pianista e professor Michel BLOCK, ${ }^{9}$ belga naturalizado americano, faz alusão ao que aprendeu sobre a cultura de Camarões, com um amigo africano natural daquele país. Na oportunidade, Block discorre sobre a importância social e cultural que aquele povo atribui ao talento de "alguém que é capaz de transmitir do intangível para o tangível", quando toca um instru- 
mento. Segundo as referências do professor, é preciso esclarecer que para a cultura de Camarões a atividade dos músicos é muito importante, já que a música existe para ser vivida ou sentida e não apenas ouvida. Sobretudo, ela é uma necessidade humana e, portanto, deve ser um valor compartilhado. A partir da análise desses valores e das próprias experiências como músico e como professor, o pianista apresenta a sua concepção de que o talento musical é "uma identificação natural com a própria linguagem da música e com os blocos construtivos desta linguagem". A estas ponderações pode ser acrescida outra dimensão que o compositor Arthur Honegger oferece quando se refere ao talento: "É preciso que se tenha a coragem de recomeçar três, quatro, cinco vezes. Esta foi a definição que, respondendo a uma enquete, eu dei sobre o talento: A Coragem de Recomeçar" (Honegger, in RAPIN, J.J.,1980, v.1, p.6)

Para a identificação natural entre o sujeito e a música, apontada por Block, acreditamos na existência de condições favoráveis, comumente encontradas nos perfis dos músicos que se destacam. Dentre elas ressaltamos a aptidão mental - revelada em características pessoais como, por exemplo, inteligência, intuição, sensibilidade, expressividade, curiosidade, concentração, flexibilidade e disciplina - e uma qualidade de aptidão, ou prédisposição física, que necessita do trabalho direcionado ao bom aproveitamento de características anatômicas e motoras. Entretanto, por julgarmos não ser esta uma questão objetiva, tampouco imprescindível, não é nossa intenção fazer um inventário de habilidades, tendências ou condições pessoais inerentes ao talento. Por este motivo, parece-nos interessante, dentre outras, a possibilidade de entendermos o talento musical como uma capacidade diferenciada de viver, sentir e compartilhar a música, adotando-se um significado semelhante ao que essas ações têm na cultura africana mencionada pelo professor Block. Entendemos, por consequência, que abordagens pedagógicas talentosas visam estimular os indivíduos para que persistam - ou recomecem várias vezes, de acordo com Honegger - no desenvolvimento das suas distintas capacidades.

0 pianista e professor austríaco Artur SCHNABEL (1988), ao discorrer sobre o mundo da música, menciona os mistérios intrínsecos da atração ou da indiferença, que a mesma obra pode causar nas pessoas. Ele próprio argumenta que não consegue enxergar a razão pela qual deveria produzir sons sem nenhuma participação interior neles. Com muita propriedade, estende o assunto e correlaciona estas observações com as práticas pedagógicas dos professores, ponderando que, mesmo neste campo, "devido à impressionante variedade nas disposições de musicistas, a unidade de julgamento não pode jamais ser esperada" (p.128). Schnabel acredita que um bom músico deve ser capaz de julgar se o resultado da sua interpretação corresponde, realmente, ao que deseja. Isto depende do seu talento, em cada fase do desenvolvimento. Quaisquer que sejam os seus talentos, o músico deve fazer tudo para alcançar o máximo de suas capacidades pessoais, o que requer mais um dom (p.133). Referindo-se ao seu professor polonês Leschetizky, Schnabel faz comentários sobre a sua experiência pessoal no período de estudos, valorizando o que aprendeu com seu mestre e reconhecendo a influência marcante deste em sua vida. Ao ser perguntado sobre o método utilizado por Leschetzky, foi enfático ao destacar uma importante característica de trabalho do seu professor, respondendo:

Não houve um método. Seu ensinamento era muito mais que um método. Era uma corrente que procurava libertar a vitalidade latente em cada estudante. Era direcionado à imaginação, ao gosto e à responsabilidade pessoal; não como uma cópia ou um caminho curto para o sucesso. Ele dava aos seus alunos uma tarefa, mas não uma receita (SCHNA$B E L, 1988$, p.125).

Esta avaliação demonstra que suas convicções a respeito do ensino musical não se restringem apenas à mera discussão sobre métodos específicos. 0 pensamento de Schnabel parece apontar mais claramente para a necessidade de reflexão e para a análise de alguns princípios básicos. Com esta perspectiva, percebemos afinidades entre o sentido das manifestações tanto de Schnabel, como as de Block e Honegger, e a concepção de Fernando Pessoa sobre as cinco qualidades necessárias a um intérprete. Entendemos que professor e aluno, na própria atuação, devem alimentar e libertar a vitalidade latente e a imaginação. 0 gosto e a responsabilidade pessoal são qualidades - e talentos - de quem ensina e de quem aprende, em troca permanente; neste universo não há unanimidades confortáveis, caminhos curtos, nem receitas. 0 cuidado com os pequenos detalhes pode propiciar significativas descobertas musicais, além de ser também uma atitude válida para o relacionamento entre as pessoas de forma geral e, especificamente, entre 0 professor e seu aluno. 0 exame atento das particularidades de uma obra favorece a compreensão sobre as relações - nem sempre aparentes - entre os elementos que se articulam no discurso musical. Quando desenvolvemos a nossa percepção da música podemos realçar as sutilezas que existem nas entrelinhas deste discurso, seja como intérpretes, compositores ou ouvintes. Partindo desta premissa, acreditamos que o professor de música deve valorizar as diferenças e compreender possibilidades e sutilezas do universo musical e também as sutilezas pessoais. Estas são potencialidades que cada individuo descobre no seu próprio tempo e à sua maneira. Mantendo ainda o foco na educação musical, julgamos pertinente incluir a mensagem do poeta Manoel de Barros, na qual percebemos uma espécie de sintese da abordagem de ensino que valoriza, em mínimos detalhes, os aspectos objetivos e os subjetivos, os pessoais e os musicais: "É no ínfimo que eu vejo a exuberância"."10 


\section{4 - Considerações finais sobre o ensino da música}

Entendemos que o ensino da música - desde a musicalização até formação acadêmica - é um processo situado no campo das relações humanas; pode ser analisado na perspectiva que o coloca como uma forma de interpretação e validação da vida. Esta perspectiva requer o exame minucioso dos rituais aos quais nos integramos e dos seus significados. Segundo as nossas observações, um bom profissional deve estar preparado para interpretar uma multiplicidade de situações educacionais e institucionais, com o foco nas pessoas, suas distintas personalidades e interações musicais e sociais. Para o exame e a interpretação deste conjunto mutável de possibilidades, no qual são apreendidos inúmeros sinais e significados, consideramos indispensáveis as cinco qualidades apontadas por Fernando Pessoa, em sua Nota Preliminar, transcrita no início deste texto. As 'atitudes cautas ou irônicas' que impedem a interpretação dos símbolos, também afastam o professor da interpretação de sinais sobre as necessidades e potencialidades, tanto suas quanto dos alunos. É utilizando conotação similar que Rainer M. Rilke aconseIha a um poeta principiante: "Busque o ômago das coisas, aonde a ironia nunca desce; e ao sentir-se destarte como que à beira do grandioso, examine ao mesmo tempo se essa concepção das coisas deriva de uma necessidade do seu ser" (RILKE, 1999, p.28).

Transpondo as condições primordiais aventadas por $\mathrm{F}$. Pessoa para a vivência de quem ensina, diremos que 0 bom professor deve, prioritariamente, gostar do que faz e manter a esperança ao tentar desvendar, a cada dia, o mistério do outro. É preciso desejar tocá-lo humanamente, através de um canal de comunicação aberto pela sensibilidade, e construir laços musicais e afetivos. Esta qualidade é a simpatia.

Quem ensina sempre está, ao mesmo tempo, imerso no processo de aprender e, às vezes descobre, subitamente, caminhos e correlações que antes não eram percebidas. Ficar atento aos pequenos sinais e insistir naquilo que parece estar subentendido são atitudes que podem conduzir à satisfação de soluções convincentes, embora não definitivas. Aquilo que está além do previsivel pode ser antevisto pelo professor, com o auxilio da simpatia e através de um olhar perscrutador de quem está envolvido inteiramente no processo. Esta qualidade é a intuição. sUm professor analisa, experimenta, compara e integra métodos, nos quais encontra a sustentabilidade para os seus princípios e suas premissas. Não é uma tarefa fácil, se ele não souber interpretar os impactos de suas propostas, na sua prática diária. Mais uma vez, 0 professor vai precisar do suporte dado pela simpatia e pela intuição. É preciso gostar das mudanças de rumos, de escolher rotas ainda inexploradas e ficar atento às estratégias: construir no ponto mais alto outras relações possíveis, de acordo com o que já está relacionado embaixo. 0 bom profissional sabe que ao observar, interpretar e reinterpretar resultados - objetivos ou subjetivos - as interconexões e analogias suplantam as simples descrições. Isto é saber ler do lado de dentro - "Intus legere" -, ou a qualidade da inteligência.

0 tempo e a experiência de um educador parecem imprimir no seu íntimo uma generosa disposição para acoIher suas convicções e dúvidas, em uma dualidade integrada e constante. A soma de informações e vivências, ou a sua sintese sempre em reconstrução, não seriam frutíferas se não fossem maturidade do profissional e as suas impressões pessoais, incorporadas à profundidade dos seus pensamentos. Isto não acontece no ato superficial de acumular dados estatísticos e referências, mas em outros domínios, ou, segundo a visão de Rilke, "não talvez no intelecto, que ficará atrás espantado, mas sim na sua mais intima consciência, que vigia e sabe" (RILKE, 1999, p.37). Esta qualidade é a compreensão.

Chegamos, através do roteiro de Pessoa, a uma espécie de clarividência que amplia nossa leitura das coisas do mundo e da arte. Ao olhar para a paisagem exterior, podemos nos sentir como se explicou Mario Quintana, em uma oportunidade, "Eu não tenho paredes. Só tenho horizontes..." 11 É bom transpor as paredes ou os limites que se impõem e que, em algumas situações, são construídos por nós mesmos, os professores. Em certos parâmetros, estas limitações podem nos acenar com falsas expectativas de segurança. Buscando outra perspectiva, nosso mundo interior pode ser uma fonte inesgotável de paisagens e novos horizontes. Após o rompimento de barreiras internas, surge o espaço reservado para encontros e conversações íntimas, em dimensões pessoais pouco exploradas. Afinal, nem tudo é exprimivel em palavras, e para qualquer músico esta verdade está na essência da sua arte. Segundo Fernando Pessoa, a quinta qualidade é pouco definivel, porém, seja qual for a denominação que possamos Ihe atribuir, acreditamos que a sua ausência significa o empobrecimento das relações humanas e dos rituais simbólicos. 


\section{Referências}

ABDO, S. Execução/Interpretação musical: uma abordagem filosófica, PER MUSI, v.1, Belo Horizonte: Escola de Música da UFMG, p.16-24, 2000.

ALVES, R. Cenas da Vida. São Paulo: Papirus Editora, 1997. Por uma Educação Romântica. São Paulo: Papirus Editora, 2002.

GAINZA, V. H. Mètodo para Piano - introducción a la música. Buenos Aires: Barry Editorial, 1977.

GALHOZ, M. A. D. Fernando Pessoa - Obra Poética - organização, introdução e notas. Rio de Janeiro: Editora José Aguilar Ltda, 1960.

GARDNER, Howard. Estruturas da Mente A Teoria das Inteligências Múltiplas. Sandra Costa (trad.); Porto Alegre: Artes Médicas do Sul, 1994.

KOELLREUTTER, Hans J. A Caminho da Superação dos Opostos, MúsicaHoje, Revista de Pesquisa Musical nº 02, Belo Horizonte: Departamento de Teoria Geral da Música da EMUFMG, 1994.

LIMA, S. A. [org.] Peformance \&t Interpretação Musical - uma prática interdisciplinar. São Paulo: Musa Editora Ltda., 2006. LUFT, L. Para não dizer adeus. Rio de Janeiro: Editora Record, 2005.

MAGNANI, S. Expressão e Comunicação na Linguagem da Música. Belo Horizonte: Editora UFMG, 1996.

RAPIN, J. J. Á Découverte de la Musique - vol I e II. Paris: Éditions Payot Lausanne, 1980.

RILKE, R. M. Cartas a um Jovem Poeta. São Paulo: Editora Globo, 1999.

SCHNABEL, A. My life and Music. New York: Dover, p.121-141, 1988.

SWANWICK, K. A Basis for Music Education. London: Routledge, p 40-53, 1979.

WAGNER, Jeffrey. Interview with Michel Block for Clavier Magazine: To Thine Own Self Be Ture, Maurício Veloso (Trad.) [original não editado]

1998.

Passing on the Legacy - interview with Michel Block by Jeffrey Wagner, Clavier Magazine, vol 37, january

WILLEMS, E. As Bases Psicológicas da Educação Musical. Suiça: Edições Pro-Musica, 1970.

WISNIK, J. M. O Som e o Sentido - Uma outra história das músicas. São Paulo: Editora Schwarcz, 2001.

\section{Notas}

1 Apontamento solto de Fernando Pessoa; s.d.; não assinado; inédito (GALHOZ, 1960)

2 Dicionários Aurélio (2a edição, 1986) e Houaiss (1ª edição, 2001).

3 Para E. WILLEMS (1970, p.10 e 68) não são apenas físicos e formais os elementos constitutivos da música, são elementos de vida de ordem fisiológica, afetiva e mental; tributários de uma síntese viva e, ao mesmo tempo, constitutivos dessa sintese. Os aspectos elevados da afetividade ultrapassam em valor artístico as manifestações da inteligência. Conforme o autor, são elementos afetivos supramentais a intuição (como um princípio de unidade que compreende a sensibilidade e a inteligência) e a inspiração, "na acepção mais nobre do termo". Embora o intelecto apreenda os seus efeitos, a natureza real da intuição transcende a razão.

4 Em abril de 2007, na programação semanal da série de concertos VivaMúsica da EM UFMG, Vera Guarnieri, viúva de Camargo Guarnieri, fez uma palestra sobre a sua vida e a sua obra. Expôs que, para ele, a criação literária e a musical se equiparavam no esforço para que as intenções ou impulsos criativos, nascidos da imaginação e sem aviso, resultassem numa obra de valor, resistente à crítica do próprio criador. Com relatos quase que pictóricos, dada a vivacidade na descrição de detalhes, própria de quem conviveu com o compositor de forma tão próxima, Vera Guarnieri revelou uma faceta muito especial do processo composicional de Guarnieri, o que nos reportou à avaliação de Gardner, sobre o fenômeno ou ato da composição musical. Guarnieri tinha o hábito de se levantar à noite e, depois, não se dar conta claramente do que havia acontecido durante o periodo em que se ausentava do quarto. No dia seguinte, ele próprio se espantava ao encontrar partituras manuscritas de fragmentos ou até mesmo de peças completas. Por vezes, após comentar que havia sonhado à noite com uma determinada composição (ou paisagem sonora?), ele ficava surpreso diante do seu próprio manuscrito, constatando que não havia sido um sonho. Num exercício de imaginação, podemos supor que este tipo de episódio talvez não surpreendesse o poeta Pessoa, que o atribuiria às possibilidades de um artista - possuidor das cinco qualidades indispensáveis -, inclinado a entabular conversações com certo Anjo da Guarda.

5 A nosso ver, o pensamento de H. J. Koellreutter complementa estas concepções: "A obra musical, assim como toda obra de arte, deveria ser considerada como manifestação do mundo simbólico, do mundo simbólico de um mito. Porque, como este, não é subjetiva nem objetiva, mas sim onijetiva. A palavra onijetivo refere-se a fenômenos que desconhecem a divisão rigorosa entre as realidades objetiva e subjetiva. Manifestar-se miticamente significa revelar, simbolizar o real e o irreal, o dito e o não-dito, som e silêncio. É tornar audível o que a alma sente e vive. 0 mito é afirmação e de- 
poimento. É negação e aprovação. É aceitação e recusa" (KOELLREUTTER, 1994, p. 09). 6 H. Koellreutter (1994, p. 09) apresenta uma reflexão sobre a apreciação musical: "o conteúdo de uma obra musical (...) nunca pode ser assimilado pela simples audição, mas sim, somente através da plena participação, da participação ativa e da co-autoria, por assim dizer, do ouvinte."

6 H. Koellreutter (1994, p. 09) apresenta uma reflexão sobre a apreciação musical: "o conteúdo de uma obra musical (...) nunca pode ser assimilado pela simples audição, mas sim, somente através da plena participação, da participação ativa e da co-autoria, por assim dizer, do ouvinte."

7 Modelo Espiral de Swanwick e Tillman (1986) foi o resultado de um estudo de 745 composições de 48 crianças entre 03 e 11 anos. Este trabalho durou 04 anos e teve a fundamentação teórica ampliada mais tarde, em 1994, quando Swanwick transformou-o no Modelo Psicológico do Desenvolvimento Musical.

8 Violeta Gainza recomenda que o aluno seja conduzido a viver e compreender a música através da sua prática, partindo do que lhe é próximo e familiar em direção ao conhecimento sistematizado (reconhecer e manejar estruturas básicas) e à expressão pessoal. Segundo Gainza, a criação surge naturalmente como produto de um saudável metabolismo, quando há a clareza a respeito das estruturas musicais e instrumentais. A autora defende os princípios de que a compreensão - que favorece a performance - traz extraordinária facilidade para a memorização e ainda, que é desejável e positivo incluir no repertório de iniciantes os próprios trabalhos de criação musical (GAINZA, 1977, p. 1 e 7).9 Nossas citações baseiam-se também na tradução do Professor Maurício Veloso (UFMG, 2005), feita a partir do original, não publicado na íntegra, de entrevista concedida por M. Block a Jeffrey WAGNER (1988).

9 Nossas citações baseiam-se também na tradução do Professor Maurício Veloso (UFMG, 2005), feita a partir do original, não publicado na íntegra, de entrevista concedida por M. Block a Jeffrey WAGNER (1988).

10 Barros M. Livro Sobre Nada. Rio de Janeiro: Editora Record, 1997; p. 55

11 Do livro Ora Bolas - O Humor de Mario Quintana, de Juarez Fonseca (L \& PM Pocket, R.S. 2006; p. 17).

Maria Inêz Lucas Machado é Graduada em Piano, Especialista em Educação Musical e Mestre em Estudos das Práticas Musicais, pela Escola de Música da UFMG. Professora com experiência pedagógica e administrativa, inclusive em projetos e cursos diversos de Extensão, exerce atualmente o segundo mandato como Vice-Diretora da Escola de Música da UFMG. Atua em disciplinas do núcleo comum - percepção musical, treinamento auditivo, piano complementar - com ênfase em performance e educação musical. Áreas de interesse, estudos e trabalhos publicados em temas tais como as dinâmicas da formação básica, intermediária e acadêmica em música, a Extensão e a Graduação em Música na Universidade Pública, com diagnósticos a partir da experiência e de opiniões docentes e discentes, além de estudos documentais. 